\title{
TEORIA HISTÓRICO-CRÍTICA: O CAMINHO PARA UMA EducaÇão Profissional E TECNOLÓgICA EMANCIPADORA
}

\author{
HISTORICAL-CRITICAL THEORY: THE PATH TO AN EMANCIPATORY \\ PROFESSIONAL AND TECHNOLOGICAL EDUCATION
}

DOI: http://dx.doi.org/10.23926/RPD.2526-2149.2018.v3.n2.p768-780.id261

\author{
Paulo de Sá Filho \\ Mestrando em Educação \\ Profissional e Tecnológica \\ (IFGoiano). \\ prof.paulo@hotmail.com.br
}

\section{Cláudia Caetano Gonçalves Mendes \\ Lima}

Mestranda em Educação

Profissional e Tecnológica

(IFGoiano).

claudia.caetanogoncalves@g mail.com

\section{Léia Adriana da Silva Santiago}

Pós doutora em Educação pela (UAB/Barcelona).

Professora EBTT

(IFGoiano).

leia.adriana@ifgoiano.edu.br

\section{Marco Antônio de Carvalho}

Pós-doutor en el currículo y la formación profesional agrícola (UAB/Barcelona). Professor Titular (IFGoiano). marco.carvalho@ifgoiano.ed $\underline{\text { u.br }}$
Resumo: No campo da educação há diversas teorias pedagógicas, as quais podem ter um caráter reprodutor ou transformador. Por exemplo, a teoria Histórico-Crítica, fundamento desse estudo, possui uma natureza emancipadora, portanto se propõe a romper com o modelo reprodutivista e hegemônico das teorias tradicionais. Essa teoria, segundo Demerval Saviani (2013b), possui como aspecto central um viés transformador e surge como um possível caminho para o aperfeiçoamento das práticas educativas no sistema educacional, em especial a Educação Profissional e Tecnológica - EPT, tendo como foco a formação omnilateral dos indivíduos, ou seja, sua capacitação profissional e desenvolvimento de senso crítico quanto à cidadania. Assim, essa pesquisa visa compreender como uma teoria pedagógica de caráter democrático pode contribuir para o processo formativo na EPT, sob a ótica da formação integral. Para constatar isso, utilizamos como método de pesquisa a revisão bibliográfica, observando a prática educativa em três pilares: o pleno desenvolvimento da pessoa, concepção omnilateral; seu preparo para o exercício da cidadania, visão emancipatória; e sua qualificação para o trabalho, que vislumbra a atividade profissional como princípio educativo.

Palavras-chave: Educação Profissional e Tecnológica. Teoria Histórico-crítica. Processo Formativo.

\begin{abstract}
In the field of education there are several pedagogical theories, which can have a reproductive or transformative character. For example, historical-critical theory, the basis of this study, has an emancipatory nature, so it proposes to break with the reproductive and hegemonic model of traditional theories. This theory, according to Demerval Saviani (2013b), has as its central aspect a transformative bias and emerges as a possible path for the improvement of educational practices in the educational system, especially the Professional and Technological Education - EPT, focusing on the omnilateral formation of individuals, that is, their professional training and development of a critical sense of citizenship. Thus, this research aims to understand how a pedagogical theory of democratic character can contribute to the formative process in EFA, from the point of view of integral formation. To verify this, we used as a research method the bibliographic revision, observing the educational practice in three pillars: the full development of the person, omnilateral conception; their preparation for the exercise of citizenship, emancipatory vision; and their qualification for work, which sees professional activity as an educational principle.
\end{abstract}

Keywords: Professional and Technological Education. HistoricalCritical Theory. Formative Process. 


\section{INTRODUÇÃO}

Neste artigo apresentamos uma reflexão sobre a teoria pedagógica e a prática educativa no processo de ensino e aprendizagem, partindo do entendimento de que essa prática deve se dar de maneira reflexiva e intencional. Assim, ao compreender a ação docente na perspectiva da racionalidade pedagógica crítico-emancipatória, este estudo se embasa na concepção de pedagogia defendida por Franco (2016).

Pensando a educação sob a ótica da formação integral, propomos analisar as possíveis contribuições da teoria Pedagógica Histórico-Crítica para o aprimoramento da prática educativa, tendo como cenário a educação profissional e tecnológica - EPT. Inicialmente, levamos em consideração que é por meio do desenvolvimento de uma ação pedagógica crítica e contextualizada que o processo formativo possibilitará à educação cumprir a sua principal finalidade: "o pleno desenvolvimento do educando, seu preparo para o exercício da cidadania e sua qualificação para o trabalho", na perspectiva de sua emancipação, conforme estabelecido pelo artigo $2^{\circ}$ da Lei de Diretrizes e Bases da Educação Nacional vigente (Lei nº. 9.394/1996).

Respaldamos nossa discussão em uma revisão bibliográfica, cuja fundamentação é as teorias pedagógicas do ensino e da aprendizagem (SACRISTÁN, 1999; BERTRAND, 2011; CHARLOT, 2013; SAVIANI, 2013ab; GASPARIN, 2015; FRANCO, 2016), buscando estabelecer um diálogo com trabalhos relacionados aos processos educativos na educação profissional e tecnológica que vislumbram uma educação estruturada sob a égide do trabalho como princípio educativo e da formação integral dos sujeitos (CIAVATTA, 2005; RAMOS, 2005; SAVIANI, 2007; NOSELLA, 2007, 2009; MOURA, 2007; RODRIGUES, 2008; ARAUJO e RODRIGUES, 2010; FRIGOTTO, CIAVATTA e RAMOS, 2005).

Para tanto, o artigo foi estruturado em três seções: a seção 1 aponta as considerações sobre teoria e prática educativa, nas perspectivas crítica e emancipatória; a seção 2 discute os pressupostos teóricos da Pedagogia Histórico-Crítica, buscando ainda verificar suas possíveis contribuições para uma ressignificação da prática educativa no âmbito da educação profissional e tecnológica; a seção 3 apresenta como uma teoria pedagógica, cujos princípios são democráticos, pode contribuir para o processo formativo na EPT. Por fim, as considerações finais, retomam sinteticamente as principais ideias apresentadas ao longo do trabalho. 


\section{REFERENCIAL TEÓRICO}

\subsection{TEORIA E PRÁTICA EDUCATIVA NAS PERSPECTIVAS CRÍTICA E EMANCIPATÓRIA}

A escola de hoje se configura como um espaço de tensão social, tendo em vista as possibilidades de ascensão econômica e social que se abrem a partir do processo educativo (CHARLOT, 2013). Sobre essa educação oferecida nos sistemas de ensino tradicionais, Ianni (2005) ressalta que esta:

[...] contribui decisivamente para a formação cultural do indivíduo e da coletividade, compreendendo as condições de transformação da população em povo, sendo este uma coletividade de cidadãos; todos seres sociais em condições de se inserirem nas mais diversas formas de sociabilidade e nos mais diversos jogos de forças sociais (IANNI, 2005, p. 32).

É neste contexto que a prática docente se insere no campo da responsabilidade social. Assim, entendemos que as análises sobre o desenvolvimento da prática educativa devem alcançar um novo patamar, pensando para além de roteiros didáticos ligados a transmissão de conteúdos pelos professores. De modo que a construção do saber deve se dar a partir da mediação e da reflexão constante destes profissionais sobre a sua própria prática. Isso implica compreender a ação educativa para além da técnica, considerando, dentre outros aspectos, a subjetividade decorrente dos atores envolvidos no processo. Sobre esse envolvimento pessoal, Sacristán (1999) argumenta que:

A educação reveste-se inexoravelmente, da condição humana, aproveita-se dela, afeta a mesma, é constituída por ela. Paralelamente, pode-se argumentar que os professores expressam-se como pessoas em suas ações, mostram-se como sujeitos, que graças a essas mesmas ações vão-se constituindo como docentes. $\mathrm{O}$ envolvimento pessoal na ação educativa é uma característica da prática com as possibilidades e os riscos que daí decorrem. Estas são afirmações elementares que têm consequências decisivas na hora de revelar e caracterizar a condição da prática educativa (SACRISTÁN, 1999, p. $32)$.

Deste modo, a ação desenvolvida pelo docente é influenciada por experiências singulares, características da condição humana. Outro aspecto complexo, apontado por Sacristán (1999), que deve ser considerado para se compreender a prática educativa numa perspectiva mais ampla é a influência exercida por outras formas de ação, externas à relação estabelecida dentro do ambiente escolar:

[...] o significado de prática educativa mais comumente aceito entre os que falam, estudam, pesquisam e realizam a educação institucionalizada é o que faz referência à prática didática que envolve estudantes, professores, currículo e os meios para seu desenvolvimento, em um âmbito de organização escolar definido. Essa realidade é bastante influenciada por outras formas de ação sobre os sistemas educativos que condicionam os marcos de desenvolvimento da ação dos docentes, sem que, na maioria dos casos, estes possam escapar de suas determinações (SACRISTÁN, 1999, p. 92). 
Ter consciência dessas ações, externas à prática docente, é determinante para se pensar em um exercício educativo contextualizado e crítico. Consonante com esse olhar, Franco (2016) conceitua a docência como uma ação relacional, mediada por múltiplas determinações, como: realidade local e específica, subjetividades e constituição histórica dos indivíduos. A autora ainda discute que para que o fazer educativo se configure como uma prática de cunho pedagógico é preciso que haja pelo menos dois movimentos: o da vigilância crítica, realizada com planejamento, acompanhamento e responsabilidade social e o da consciência das intencionalidades que norteiam suas práticas.

Essa ação consciente e participativa nos remete a uma compreensão de pedagogia voltada para a racionalidade pedagógica crítico-emancipatória, cujo princípio básico repousa na historicidade enquanto condição para se compreender o conhecimento. Sobre os objetivos desta ação pedagógica Franco (2016) nos diz que:

[...] a questão direcionada à Pedagogia será a de formação de indivíduos "na e para a práxis", conscientes de seu papel na conformação e na transformação da realidade sócio-histórica, pressupondo sempre uma ação coletiva, ideologicamente constituída, por meio da qual cada sujeito toma consciência do que é possível e necessário, a cada um, na formação e no controle da constituição do modo coletivo de vida. A formação humana é valorizada no sentido das condições de superação da opressão, submissão e alienação, do ponto de vista histórico, cultural ou político. Considera-se que a proposta de projetos político-pedagógicos, como organizadores da esfera pedagógica da escola, parte dessa perspectiva teórica. (FRANCO, 2016, p. 540).

Nesse sentido, a concepção pedagógica crítico-emancipatória, voltada para um processo formativo contextualizado, busca a transformação do indivíduo e da sociedade. Tendo isso em vista, é de fundamental importância refletir, no contexto atual, sobre as possíveis contribuições da teoria Pedagógica Histórico-Crítica para as práticas educativas no âmbito da Educação Profissional e Tecnológica (EPT).

\subsection{Pressupostos teóricos e a POSSíVEl RESSIGNifiCAÇÃo da PRÁtica EDUCATIVA} NO ÂMBITO DA EDUCAÇÃO PROFISSIONAL E TECNOLÓGICA

A década de 1980 no Brasil foi palco de grandes debates sobre a educação. O processo de redemocratização tornou evidente a insatisfação existente com a política educacional do regime civil-militar, que se pautava no "ajustamento dos aparelhos ideológicos do Estado utilizados como instrumentos de controle da sociedade, visando a perpetuar as relações de dominação vigentes". (SAVIANI, 2013a, p. 114)

No âmbito da educação profissional, Ramos (2005) enfatiza as reivindicações apresentadas naquela década por estudiosos, educadores e demais profissionais da área por uma educação nacional que fosse unitária, politécnica e omnilateral, capaz de superar a dualidade 
histórica da formação para o trabalho manual e para o trabalho intelectual, aspirando por um projeto de educação comprometido com a classe trabalhadora.

Considerando que a educação assume um papel de reprodução da estrutura social capitalista e de suas contradições, Dermeval Saviani publica, no ano de 1983, o livro Escola e Democracia, onde apresenta os elementos de uma nova teoria crítica, que no ano seguinte receberia o nome de Pedagogia Histórico-Crítica. Sobre o sentido básico dessa expressão, Saviani (2013b) nos diz que:

Essa formulação envolve a necessidade de se compreender a educação no seu desenvolvimento histórico-objetivo e, por consequência, a possibilidade de se articular uma proposta pedagógica cujo ponto de referência, cujo compromisso, seja a transformação da sociedade e não sua manutenção, a sua perpetuação. (SAVIANI, 2013b, p. 80).

Saviani (2013a) enfatiza que apesar do clima favorável ao surgimento das pedagogias contra-hegemônicas nos anos de 1980, a concretização de políticas educativas de caráter crítico e emancipatório fracassou, culminando, na década de 1990, na ascensão de ideários neoliberais advindos do denominado Consenso de Washington. Todavia, a teoria Pedagógica HistóricoCrítica ainda se mostra atuante, como evidencia as sucessivas edições dos livros Escola $e$ Democracia e Pedagogia Histórico-Crítica: primeiras aproximações, ambas de autoria de Dermeval Saviani e ainda, o surgimento de novos trabalhos desenvolvendo essa perspectiva pedagógica, dentre elas a obra Uma Didática para a Pedagogia Histórico-Crítica, de João Luiz Gasparin.

Em Pedagogia Histórico-Crítica: primeiras aproximações, Saviani defende a ideia de que a educação deve ser compreendida como uma mediação no seio da prática social global, cabendo a esta possibilitar às novas gerações a incorporação dos elementos herdados, produzidos histórica e conjuntamente, de maneira a torná-las ativas no processo de transformação das relações sociais. Para o autor, a instituição escolar deve "propiciar a aquisição dos instrumentos que possibilitem o acesso ao saber elaborado (ciência), bem como o próprio acesso aos rudimentos desse saber [...]" (SAVIANI, 2008, p. 15). O saber elaborado é o conhecimento construído historicamente pelos homens, "[...] é aquilo que se firmou como fundamental, como essencial [...]" (SAVIANI, 2008, p. 14).

No campo da prática, a escola deve dosar e sequenciar o conhecimento e, através da mediação (do abstrato), possibilitar que o educando passe de uma visão sensorial imediata (sincrética) para uma visão concreta, sintética da realidade. Já o educador precisa ter "clareza dos determinantes sociais da educação", compreender em que nível as contradições da 
sociedade marcam a educação", para assim se posicionar e "perceber claramente qual é a direção que cabe imprimir à questão educacional”. (SAVIANI, 2013b, p. 86)

Partindo dessa perspectiva, João Luiz Gasparin, em seu livro Uma Didática para a Pedagogia Histórico-Crítica, apresenta por meio de cinco passos como delinear a prática pedagógica segundo a concepção metodológica dialética proposta por Saviani, a saber: prática social inicial do conteúdo, problematização, instrumentalização, catarse e prática social final do conteúdo. Assim, a prática social inicial busca trazer para dentro da sala de aula a vivência do educando sobre o conteúdo que será abordado, de maneira a estabelecer uma relação deste com a realidade. Segundo Gasparin,

O primeiro passo do método caracteriza-se por uma preparação, uma mobilização do aluno para a construção do conhecimento escolar. É uma primeira leitura da realidade, um contato inicial com o tema a ser estudado [...] Uma das formas para motivar os alunos é conhecer sua prática social imediata a respeito do conteúdo curricular proposto. (2015, p. 13).

No segundo passo, tem-se a problematização e a discussão das diferentes dimensões do conteúdo (conceitual, histórica, social, política, etc.), configurando "o processo de busca, de investigação para solucionar as questões em estudo, [como] o caminho que predispõe o espírito do educando para a aprendizagem significativa" (GASPARIN, 2015, p. 33).

$\mathrm{O}$ terceiro passo é marcado pela mediação do professor entre o conhecimento e os educandos, no qual o conteúdo é trabalhado de forma sistematizada, na busca por solucionar as questões levantadas na etapa anterior. Esse processo é denominado de instrumentalização, visto que

[...] parte-se do conhecimento que se tem (sincrético) e aos poucos (pela mediação da análise) este conhecimento anterior vai se ampliando, negando, superando, chegando a um conhecimento mais complexo e abrangente (sintético $=$ 'concreto') [...] (VASCONCELLOS, 1993, p. 64 apud GASPARIN, 2015, p. 50).

A catarse (quarto passo) é o momento em que o educando irá traduzir por escrito ou expor oralmente a sua compreensão de todo o processo, expressando, a seu modo, "sua nova maneira de ver o conteúdo e a prática social. É capaz de entendê-los em um novo patamar, mais elevado, mais consistente e mais bem estruturado" (GASPARIN, 2015, p.127). Este momento é favorável aos mecanismos avaliativos.

A prática social final do conteúdo é o alcance da visão concreta pensada, em que o educando apresenta ações ou intenções com base no conteúdo aprendido, capazes de promover uma transformação da sua realidade social. Sobre a abrangência desse passo, Gasparin (2015) afirma que o desenvolvimento de "ações reais e efetivas" ultrapassam o fazer material, pois é nesse processo mental que se "possibilita [a] análise e [a] compreensão mais amplas e críticas 
da realidade, determinando uma nova maneira de pensar, de entender e julgar os fatos [...]" (GASPARIN, 2015, p. 140)

De acordo com Gasparin e Petenucci (2013), desenvolver a prática pedagógica de acordo como os cinco passos descritos acima, exige uma nova forma de trabalhar os conteúdos, numa perspectiva contextualizada nas mais diversas áreas do conhecimento humano, de maneira a evidenciar:

[...] que este advém da história produzida pelos homens nas relações sociais de trabalho. Essa didática objetiva um equilíbrio entre teoria e prática, envolvendo os educandos em uma aprendizagem significativa dos conhecimentos científicos e políticos, para que estes sejam agentes participativos de uma sociedade democrática e de uma educação política. (Gasparin e Petenucci, 2013).

Diante disso, é possível estabelecer uma relação entre a proposta metodológica da pedagogia histórico-crítica, que parte de uma abordagem do conteúdo de maneira contextualizada, buscando a integração entre teoria e prática, e um dos eixos norteadores da educação profissional e tecnológica, o trabalho como princípio educativo. Frente ao campo normativo, essa ação didático-pedagógica comprometida com o trabalho, numa perspectiva de integração entre teoria e prática, dialoga com as premissas da educação profissional estabelecidas nos itens III e IV do artigo $2^{\circ}$, do Decreto $\mathrm{n}^{\circ} 5.154$, de 23 de julho de 2004, a saber: a centralidade do trabalho como princípio educativo e a indissociabilidade entre teoria e prática, respectivamente.

Para além desse dispositivo legal, que regulamenta a organização da educação profissional no Brasil, é preciso considerar que no campo teórico os pesquisadores brasileiros da educação, sobretudo os envolvidos nos debates da modalidade profissional e tecnológica (FRIGOTTO, CIAVATTA e RAMOS, 2005; RAMOS, 2005; NOSELLA, 2007; MOURA, 2007; CIAVATTA, 2008; RODRIGUES, 2008) têm defendido uma posição contra hegemônica nos processos formativos que, a partir da perspectiva crítica e emancipatória, possibilite trilhar um caminho de superação ao modelo de educação centrado na lógica produtivista e de mercado, imposta pelo sistema capitalista.

\section{MÉTOdos}

Para Parra Filho e Santos (1998, p. 97), “qualquer que seja o campo a ser pesquisado, sempre será necessária uma pesquisa bibliográfica, para se ter um conhecimento prévio do estágio em que se encontra o assunto". No mesmo sentido, Oliveira (2004, p. 119) atesta que “a Pesquisa bibliográfica tem por finalidade conhecer as diferentes formas de contribuição científica que se realizaram sobre determinado assunto ou fenômeno", ou seja, podemos aferir 
que esse tipo de estudo se fundamenta em informações e dados para justificar ou não a existência de uma determinada hipótese. Dito isso, a nossa pesquisa tem cunho bibliográfico.

Dessa maneira, a problemática e os objetivos desse estudo, estão baseados em pesquisas já realizadas, sendo possível a interlocução com outras fontes já divulgadas, tendo como foco a solução do problema e o alcance dos objetivos propostos. De acordo com Marconi e Lakatos (2001, p. 44) a "finalidade é colocar o pesquisador em contato direto com tudo aquilo que foi escrito sobre determinado assunto". Sobre essa ótica, analisamos pesquisas cujos temas estavam relacionados à teoria Pedagógica Histórico-Crítica e à educação profissional e tecnológica, fundamentadas em propostas de uma educação crítica, reflexiva e transformadora, portanto emancipatória, propondo o trabalho como princípio educativo e a formação omnilateral do indivíduo.

\section{Resultados}

Ao questionar como uma teoria pedagógica de viés democrático pode contribuir para o processo formativo na EPT, acreditamos na necessidade de que qualquer proposta didáticopedagógica esteja em consonância com o que preconiza a Constituição nacional, no que tange à educação e sua finalidade. Assim, tomamos como base o artigo 205 da Constituição Federal Brasileira, que estabelece:

A educação, direito de todos e dever do Estado e da família, será promovida e incentivada com a colaboração da sociedade, visando ao pleno desenvolvimento da pessoa, seu preparo para o exercício da cidadania e sua qualificação para o trabalho (BRASIL, 1988).

De acordo como os fundamentos teórico-críticos de Saviani (2010), que consideram a base legal da educação brasileira, tais objetivos:

\footnotetext{
se referem indistintamente a todos os membros da sociedade brasileira considerados individualmente, [assim], podemos interpretar, com Gramsci (1975, vol. III, p. 1547), que o objetivo da educação é conduzir cada indivíduo até a condição de ser capaz de dirigir e controlar quem dirige.(SAVIANI, 2010, p. 387)
}

Com isso, conjecturar sobre essas três finalidades torna-se primordial para que possamos entender de que maneira uma teoria pedagógica democrática, no caso em questão a teoria Histórico-Critica, irá contribuir com o processo formativo da educação profissional, na concepção integral.

\subsection{Pleno desenVolvimento da PeSsoA}

Nessa perspectiva de pleno desenvolvimento da pessoa, é preciso reconhecer cada indivíduo como um ser que aprende e que ensina constantemente, assim, reconhecendo-o como 
sujeito humano, social e cultural (ARROYO, 2004). Dessa maneira, deve-se propor um projeto pedagógico que possibilite que todos tenham seus direitos garantidos e que oportunize todas as maneiras de inclusão, pois, como indica Padilha (2012, p. 247), isso significa educar integralmente.

Como aponta Nosella (2007, p. 147), para construir essa escola que oferece atividades formativas, com grande rigor formal e disciplinar, é preciso, também, oferecer o exercício responsável da liberdade e o desenvolvimento dos talentos individuais. Para Ramos (2005, p 3), uma educação dessa natureza precisa ser politécnica; isto é: uma educação que, ao propiciar aos sujeitos o acesso aos conhecimentos e à cultura construídos pela humanidade, promova a realização de escolhas e a construção de caminhos para a produção da vida. Com essa concepção de educação plena, podemos entender que há uma inter-relação entre trabalho, ciência e cultura, em que o trabalho atua como princípio educativo, a ciência, como os conhecimentos produzidos pelo homem ao longo do tempo, e a cultura, como valores e regras de uma comunidade (RAMOS, 2005).

\subsection{Preparo para o exercício da Cidadania}

A respeito dessa finalidade, que estabelece que a educação deve preparar para o exercício da cidadania, é preciso destacar, que ao discutir o significado de cidadania, devemos observá-lo como um conceito histórico, em virtude de sua mudança ao longo do tempo e o espaço (PINSKY e PINSKY, 2003). Assim, torna-se oportuno expor o que dizem Frigotto e Ciavatta sobre o conceito de cidadania na sociedade brasileira,

o conceito de cidadania parece um conceito pouco elaborado entre nós. Não apenas por carência de reflexão, mas porque a própria questão da cidadania é, originalmente, uma questão alheia à constituição da sociedade brasileira pós-colonial, situação que teria se prolongado sob o fenômeno da exclusão dos "cidadãos" brasileiros de diversas instâncias da vida social (2003, p. 53).

Tal afirmativa, da falta de um conceito sólido de cidadania na sociedade brasileira, permite conceber que é vital que rompamos com a lógica hegemônica e excludente que permeia a sociedade brasileira. Nesse sentindo, o exercício da cidadania deve partir de uma concepção dialética, ou seja, que nasce,

Somente quando o homem individual real recupera em si o cidadão abstrato e sem converte, como homem individual, em ser genérico, em seu trabalho individual e em suas relações individuais; somente quando o homem tenha reconhecido e organizado suas próprias forças como forças sociais e quando, portanto, já não separa de si a força social sob a forma de força política, somente então se processa a emancipação humana" (MARX, op. cit., p. 52, apud. FRIGOTTO e CIAVATTA, 2003, p. 56) 
Em síntese, essa concepção de cidadania está intimamente relacionada à liberdade política, à igualdade social, ao direito ao trabalho, à terra, à associação, à saúde e à educação (ARROYO, 1982, p. 5), e deve ser oportunizada a todos os indivíduos, independentemente de sua classe social. Com isso, uma formação educacional que preconize o exercício a esse tipo de cidadania só pode ser concebida por meio de uma teoria pedagógica crítica.

Nesse sentido, é necessário que cada indivíduo, em uma perspectiva histórico-dialética, pense e reflita de maneira crítica sobre a sociedade contemporânea, promovendo por meio dessa práxis, a diminuição das desigualdades e rompendo com a cultura hegemônica existente, buscando, como afirma Gadotti, (2014, p. 1), formar o cidadão para participar, com responsabilidade, do destino de seu país.

\subsection{QUALIFICAÇÃO PARA O TRABALHO}

Ao observar a qualificação para o trabalho, há de se evidenciar que na concepção de educação emancipatória, objetiva-se uma formação para o mundo do trabalho e não para o mercado, tendo em vista que essa perspectiva contempla o trabalho como princípio educativo. Essa ótica percebe o trabalho em seu sentido ontológico, ou seja, como a ação humana de interação com a realidade para a satisfação de necessidades e para a produção de liberdade, não apenas como ação econômica.

Assim, a qualificação para trabalho deve romper com a lógica mercadológica da sociedade contemporânea, que possui um caráter econômico, vislumbrando atender apenas as necessidades do mercado, sem incorporar valores ético-políticos e conteúdos históricos e científicos, caracterizados no ideal de práxis, a fim de, unicamente, preparar os indivíduos para o mundo do trabalho, tornando-os aptos para o exercício autônomo e crítico de suas profissões e, também, para enfrentar as dinâmicas sócio-produtivas das sociedades contemporâneas (RAMOS, 2005).

\section{CONSIDERAÇÕES FINAIS}

A teoria pedagógica Histórico-Crítica busca romper com o caráter reprodutor da pedagogia tradicional. Para este trabalho, essa teoria foi apresentada como mecanismo de aprimoramento das práticas educativas na educação profissional e tecnológica - EPT, tendo como horizonte a formação integral. Conforme conceitua Bertrand, "as teorias da educação são conjuntos sistematizados das percepções e das representações que as pessoas têm da organização da educação e que são utilizadas na evolução desta organização" (2001, p. 9). 
Assim, Dermeval Saviani, no que diz respeito à teoria histórico-crítica, compreende a educação como uma mediação no seio da prática social global, cabendo a esta possibilitar às novas gerações a incorporação dos elementos herdados, produzidos histórica e conjuntamente, de modo a torná-los agentes ativos no processo de ação e transformação das relações sociais (SAVIANI, 2013b). Portanto, entendemos que é imprescindível que as práticas educativas tenham caráter reflexivo e intencional, que o diálogo estabelecido entre aluno, professor e conhecimento se dê a partir de uma perspectiva dialética, uma vez que a educação é um processo histórico, que requer um movimento de contextualização e de ponderação das múltiplas determinações que a perpassam enquanto prática social.

Além disso, é importante destacar, que nesse âmbito, o desenvolvimento de uma prática pedagógica comprometida com a emancipação dos sujeitos assume grande relevância social, tendo em vista sua intrínseca relação com a classe que vive do trabalho. Porém, diante dessa dinamicidade nas relações sociais internas e externas ao processo educativo, e que permeiam as produções e estudos sobre a educação, é preciso considerar as limitações que surgem para a aplicação da referida teoria, sem com isso desconsiderar o seu importante papel enquanto referência teórica para o avanço no campo da prática educativa. Espera-se que este estudo suscite em profissionais docentes o interesse em estabelecer um diálogo entre suas ações e as produções do campo teórico, sobretudo, com as teorias da educação, para que a prática educativa possa se tornar cada dia mais reflexiva e crítica, tendo como horizonte a emancipação dos sujeitos e a consequente transformação da realidade.

\section{REFERÊNCIAS}

ARROYO, M. G. Imagens quebradas. Trajetórias e tempos de alunos e mestres. Petrópolis: Vozes, 2004.

ARROYO, M. G. Escola, Cidadania e Participação no Campo. Disponível em:< http://emaberto.inep.gov.br/index.php/emaberto/article/view/1400> Acesso em 11 jul. 2018.

BERTRAND, Y. Teorias contemporâneas da educação. Lisboa: Instituto Piaget, 2001.

BRASIL. Lei de Diretrizes e Bases da Educação Nacional n. 9.394/1996. Brasília: Senado Federal, 1996.

BRASIL. Decreto $\mathbf{n}^{0}$ 5.154. Regulamenta o $§ 2^{\circ}$ do art. 36 e os arts. 39 a 41 da Lei no 9.394, de 20 de dezembro de 1996, que estabelece as diretrizes e bases da educação nacional, e dá outras providências, 2004.

CHARLOT, B. Da relação como o saber às práticas educativas. São Paulo: Cortez, 2013. 
FRANCO, M. A. do R. S. Prática pedagógica e docência: um olhar a partir da epistemologia do conceito. Estudos Pedagógicos, 97, 534-551, 2016.

FRIGOTTO, G.; CIAVATTA, M.; RAMOS, M. (orgs.). Ensino médio integrado: concepção e contradições. São Paulo: Cortez, 2005.

FRIGOTTO, G. A relação da educação profissional e tecnológica com a universalização da educação básica. Educação \& Sociedade, 28, 1129-1152, 2007.

FRIGOTTO, G.; CIAVATTA, M. Trabalho, Educação e Saúde. Disponível em: $<$ http://www.scielo.br/scielo.php?pid=S1981-

$77462003000100005 \&$ script=sci_abstract\&tlng=pt $>$ Acesso em 11 jul. 2018.

GADOTTI, M. Gestão Democrática com Participação Popular: no planejamento e na organização da educação nacional. Disponível em http://conae2014.mec.gov.br/images/pdf/artigogadotti_final.pdf> Acesso em 11 jul. 2018.

GASPARIN, J.L; PETENUCCI, M. C. Pedagogia histórico-crítica: da teoria a prática no contexto escolar. Campinas: Autores Associados, 2013.

GASPARIN, J. L. Uma didática para a pedagogia histórico-crítica. Campinas: Autores Associados, 2015.

IANNI, Octavio. $O$ cidadão do mundo. In: LOMBARDI, José Claudinei; SAVIANI, Dermeval; SANFELICE, José Luís (org.). Capitalismo, trabalho e educação. 3 ed. Campinas: Autores Associados, HISTEDER, 2005.

LAKATOS, E. M.; MARCONI, M. A. Metodologia do trabalho científico: procedimentos básicos, pesquisa bibliográfica, projeto e relatório, publicações e trabalhos científicos. 6 ed. São Paulo: Atlas, 2001.

MOURA, D. H. Educação básica e educação profissional e tecnológica: dualidade histórica e perspectiva de integração. Revista Holos, 2, 1-27, 2007.

NOSELLA, P. Trabalho e perspectivas de formação dos trabalhadores: para além da formação politécnica. Revista Brasileira de Educação, 12, 137-181, 2007.

OLIVEIRA, S. L. Tratado de Metodologia Científica: projetos de pesquisas, TGI, TCC, monografias, dissertações e teses. São Paulo: Pioneira Thomson Learning, 2004.

PADILHA, P. R. Educar em Todos os Cantos: reflexões e canções por uma educação intertranscultural. São Paulo: Editora e Livraria Instituto Paulo Freire, 2012.

PARRA FILHO, D.; SANTOS, J. A. Metodologia Científica. São Paulo: Futura, 1998.

PINSKY, C. B.; PINSKY, J. (org). História da cidadania. São Paulo: Contexto,2003.

RAMOS, M. Concepção do Ensino Médio Integrado. São Paulo: Cortez, 2005.

RODRIGUES, J. A educação politécnica. Campinas: Autores Associados, 1998. 
SACRISTÁN, J. G. Poderes instáveis em educação. Porto Alegre: Artes Médicas Sul, 1999.

SAVIANI, D. Trabalho e educação: fundamentos ontológicos e históricos. Revista Brasileira de Educação, 12, 52-180, 2007.

SAVIANI, D. Escola e democracia: teorias da educação, curvatura da vara, onze teses sobre a educação política. 39 ed. Campinas: Autores Associados, 2008.

SAVIANI, D. Sistema Nacional de Educação articulado ao Plano Nacional de Educação. Disponível em:< http://www.scielo.br/pdf/rbedu/v15n44/v15n44a13.pdf > Acesso em 11 jul. 2018.

SAVIANI, D. História das ideias pedagógicas no Brasil. Campinas: Autores associados, 2013a.

SAVIANI, D. Pedagogia histórico-crítica: primeiras aproximações. Campinas: Autores associados, 2013b.

Recebido em: 13 de setembro de 2018.

Aprovado em: 3 de outubro de 2018. 